\title{
SATURATION SPECTRUM OF PATHS AND STARS
}

\author{
JiLL FAUDREE \\ Department of Mathematics and Statistics \\ University of Alaska Fairbanks \\ e-mail: jrfaudree@alaska.edu \\ RALPH J. FAUdREE \\ Department of Mathematical Sciences \\ University of Memphis \\ Ronald J. Gould \\ Department of Mathematics and Computer Science \\ Emory University \\ e-mail: rg@mathcs.emory.edu \\ Michael S. JaCOBSON \\ AND \\ Brent J. Thomas \\ Department of Mathematics and Statistical Sciences \\ University of Colorado Denver \\ e-mail: michael.jacobson@ucdenver.edu \\ brent.thomas@ucdenver.edu
}

\begin{abstract}
A graph $G$ is $H$-saturated if $H$ is not a subgraph of $G$ but the addition of any edge from $\bar{G}$ to $G$ results in a copy of $H$. The minimum size of an $H$-saturated graph on $n$ vertices is denoted $\operatorname{sat}(n, H)$, while the maximum size is the well studied extremal number, $\operatorname{ex}(n, H)$. The saturation spectrum for a graph $H$ is the set of sizes of $H$ saturated graphs between sat $(n, H)$ and $\operatorname{ex}(n, H)$. In this paper we completely determine the saturation spectrum of stars and we show the saturation spectrum of paths is continuous from $\operatorname{sat}\left(n, P_{k}\right)$ to within a constant of $\operatorname{ex}\left(n, P_{k}\right)$ when $n$ is sufficiently large.
\end{abstract}

Keywords: saturation spectrum, stars, paths.

2010 Mathematics Subject Classification: 05C35, 05C05. 


\section{REFERENCES}

[1] K. Amin, J. Faudree and R.J. Gould, The edge spectrum of $K_{4}$-saturated graphs, J. Combin. Math. Combin. Comput. 81 (2012) 233-242.

[2] K. Amin, J. Faudree, R.J. Gould and E. Sidorowicz, On the non- $(p-1)$-partite $K_{p}$-free graphs, Discuss. Math. Graph Theory 33 (2013) 9-23. doi:10.7151/dmgt.1654

[3] C. Barefoot, K. Casey, D. Fisher, K. Fraughnaugh and F. Harary, Size in maximal triangle-free graphs and minimal graphs of diameter 2, Discrete Math. 138 (1995) 93-99. doi:10.1016/0012-365X(94)00190-T

[4] G. Chartrand, L. Lesniak and P. Zhang, Graphs \& Digraphs (CRC Press, 2010).

[5] P. Erdős and T. Gallai, On maximal paths and circuits of graphs, Acta Math. Acad. Sci. Hungar. 10 (1959) 337-356.

[6] R.J. Gould, W. Tang, E. Wei and C.-Q. Zhang, The edge spectrum of the saturation number for small paths, Discrete Math. 312 (2012) 2682-2689. doi:10.1016/j.disc.2012.01.012

[7] L. Kászonyi and Zs. Tuza, Saturated graphs with minimal number of edges, J. Graph Theory 10 (1986) 203-210. doi:10.1002/jgt.3190100209

Received 29 October 2015

Revised 20 July 2016

Accepted 20 July 2016 